\title{
Concepto de proyecto de inversión
}

\author{
Investment Project Concept
}

\section{Dorie Cruz-Ramírez $z^{\mathrm{a}}$ Lizet Yoselin Rivas Rivas ${ }^{\mathrm{b}}$, Claudia Beatriz Lechuga Canto $^{\mathrm{c}}$}

\begin{abstract}
:
An investment project, represents a set of actions, activities that are related to each other in order to meet a specific purpose, can be lucrative, or not, this project requires the articulation of human, technological and financial resources to give the results that are waiting. An investment project comes from an idea represents a proposal that aims to meet the needs of a person or a group of people.
\end{abstract}

\section{Keywords:}

Investment project, Concept.

\section{Resumen:}

Un proyecto de inversión, representa un conjunto de acciones o actividades que se relacionan entre sí con la finalidad de cumplir un fin específico, puede ser lucrativo o no, dicho proyecto requiere la articulación de recursos humanos, tecnológicos y financieros para dar los resultados que se esperan. Un proyecto de inversión surge de una idea, representa una propuesta que pretende satisfacer las necesidades de una persona o un grupo de personas.

\section{Palabras Clave:}

Proyecto de inversión, Concepto.

\section{Introducción}

El presente documento muestra a manera de mapa mental, la conceptualización de lo que es un proyecto de inversión. (Figura núm. 1)

\section{Descripción}

Un proyecto de inversión representa una acción a realizar donde se pretende obtener una ganancia o un beneficio (puede ser social o no), en el intervienen factores tan relevantes como es el tiempo, ya que se establecen metas a diversos plazos como es a corto, mediano o largo.

Un proyecto de inversión evalúa elementos de la operación diaria como son la oferta y la demanda de un producto y/o servicio y requiere de diversos estudios para que el proyecto sea viable.

El proyecto de inversión, es considerado un plan en el que se invierten capitales e insumos de diferente índole como son materiales, humanos y técnicos.

El presente mapa presenta también, el objetivo que persigue un proyecto de inversión y consiste en generar un rendimiento económico a un determinado plazo.

\footnotetext{
a Autor de Correspondencia, Universidad Autónoma del Estado de Hidalgo, Escuela Superior de Cd. Sahagún, email.doriec@uaeh.edu.

b Universidad Autónoma del Estado de Hidalgo, Escuela Superior de Cd. Sahagún, email. Yoselin.rivas.uaeh@gmail.com

${ }^{c}$ Universidad Autónoma del Estado de Hidalgo, Escuela Superior de Cd. Sahagún, email. claudiablc@uaeh.edu.mx
} 


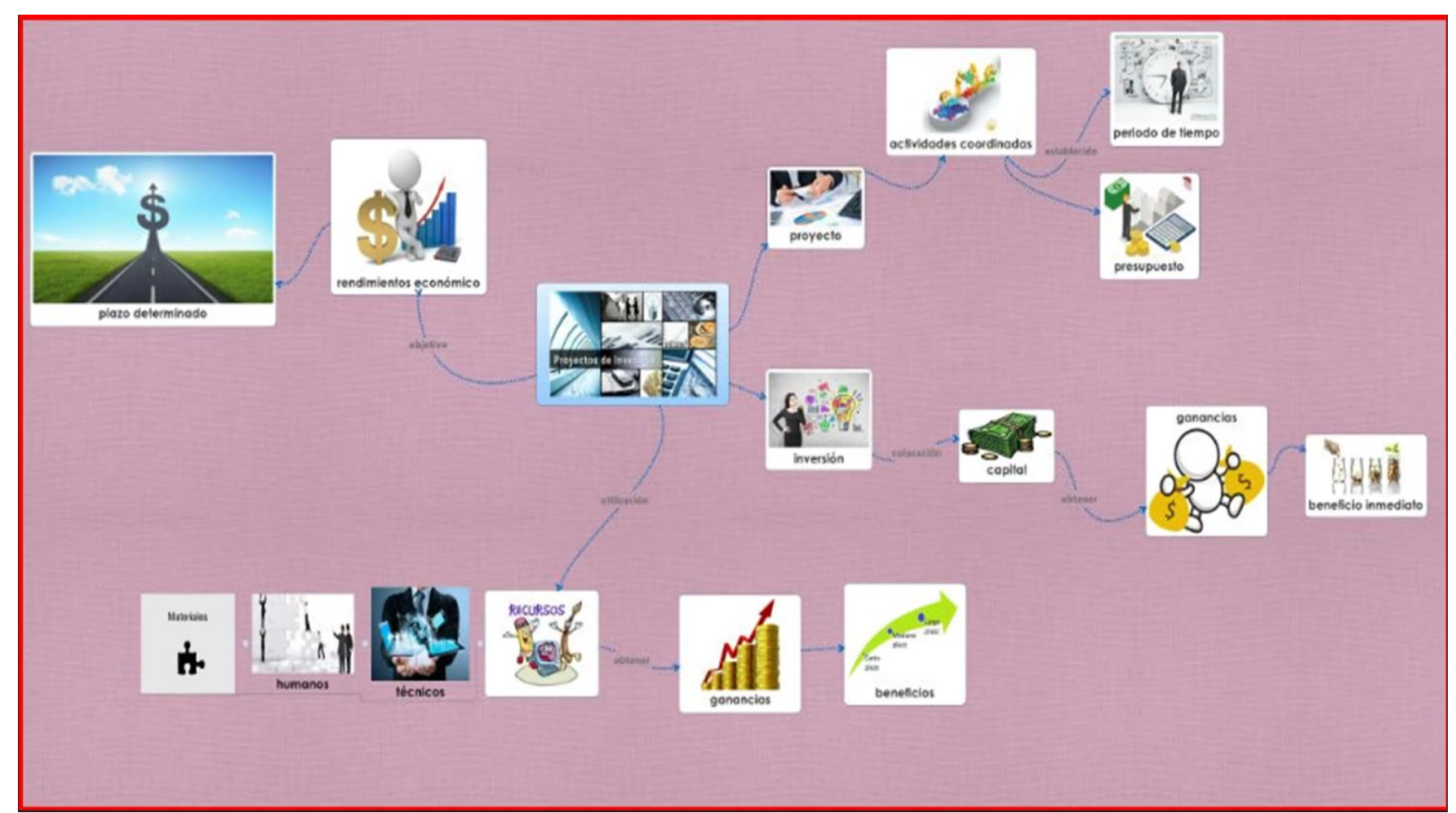

Figura 1. Concepto de proyecto de inversión

\section{Referencias}

[1] Pérez J, \& Gardey, A. (2009). Definición de proyecto de inversión. Recuperado el 02 de marzo de 2019. De https://definicion.de/proyecto-de-inversion/

\footnotetext{
a Autor de Correspondencia, Universidad Autónoma del Estado de Hidalgo, Escuela Superior de Cd. Sahagún, email.doriec@uaeh.edu.

${ }^{\mathrm{b}}$ Universidad Autónoma del Estado de Hidalgo, Escuela Superior de Cd. Sahagún, email. Yoselin.rivas.uaeh@gmail.com

${ }^{\mathrm{c}}$ Universidad Autónoma del Estado de Hidalgo, Escuela Superior de Cd. Sahagún, email. claudiablc@uaeh.edu.mx
} 